\title{
A identidade internacional do Brasil: uma síntese da literatura
}

\author{
Brazil's International Identity: \\ a synthesis of the literature
}

DOI: $10.21530 /$ ci.v11n3.2016.496

Rafael Mesquita ${ }^{1}$

\section{Resumo}

O presente artigo faz uma síntese da literatura sobre o tema da identidade internacional, bem como de suas aplicações ao caso brasileiro. Para tanto, resume os debates sobre identidade nacional e internacional, detalhando as especificidades teóricas, disciplinares e analíticas de cada um, para assim chegar a uma síntese conceitual. O esquema analítico resultante é então aplicado às interpretações da identidade internacional brasileira, repartidas em cinco "dimensões": socioeconômica, política, étnico-cultural, continental e de valores. Tal categorização ambiciona reunir narrativas prevalentes na caracterização do país e também provê um framework parcimonioso que futuras pesquisas poderão empregar e aperfeiçoar.

Palavras-chave: Identidade, Identidade Internacional do Brasil, Análise do Discurso, Construtivismo

\begin{abstract}
This study performs a synthesis of the literature on the topic of international identity, as well as of its usage in the Brazilian case. In order to do so, we summarize discussions on national and international identity, detailing theoretical, disciplinary and analytical specificities of both concepts, so as to arrive at a conceptual synthesis. The resulting analytic frame is then applied to interpretations of Brazil's international identity grouped in five "dimensions": socioeconomic, political, ethnic-cultural, continental, and values. This categorization aims to gather the prevailing narratives used to characterize the country and to provide a parsimonious framework that future researches can employ and enhance.
\end{abstract}

Keywords: Identity, Brazil’s International Identity, Discourse Analysis, Constructivism

1 Doutorando e Mestre em Ciência Política/Relações Internacionais pelo PPGCP-UFPE. Jornalista pela UFPE e Administrador pela UPE. E-mail: rafaelmesquita_5688@hotmail.com

Artigo submetido em 12/07/2016 e aprovado em 25/08/2016. 


\section{Introdução}

Qual a identidade do Brasil no mundo? Em relações internacionais (RI), sobretudo após o debate inaugurado pelo construtivismo, identidades se tornaram um elemento basilar para a compreensão do comportamento dos Estados no sistema internacional. Entretanto, indagações sobre a natureza ou o caráter de um povo são muito anteriores a essa escola, originando-se em campos diversos do saber.

Há uma interface possível entre ambas as óticas? Que pontos de contato há entre a visão internacionalista de inspiração construtivista e as reflexões mais gerais e multidisciplinares sobre identidade? O presente trabalho busca responder a essas perguntas tendo em mente o caso brasileiro. Seu objetivo é realizar duas sínteses necessárias. Primeiramente, contribuir para uma melhor compreensão da identidade, apresentando as especificidades do conceito quando abordado por perspectivas internacionalistas, principalmente as de inspiração construtivista, e por outras disciplinas. Como forma de conciliação, propõe-se uma conceituação de identidade enquanto fenômeno narrativo e prático, que adquire significado interdiscursivamente e é elaborado por uma pluralidade de atores. A segunda síntese é de ordem substantiva: busca-se agrupar as principais discussões sobre a identidade (nacional e internacional) do Brasil em cinco grandes dimensões, aplicando-lhes o esquema conceitual desenvolvido. Ao final, são apresentados comentários à título de conclusão e sugestão de agenda de pesquisa futura.

\section{Identidade internacional: precisões conceituais}

\section{Identidade internacional ou nacional?}

Há diferença entre identidade nacional e identidade internacional? Embora ambas definições sejam uma resposta à pergunta “Quem sois?” e, não raro, sejam empregadas como sinônimos, há distinções relevantes no que tange suas unidades de análise, inspiração teórica e quais disciplinas se apropriam do termo.

A identidade nacional vem sendo, tradicionalmente, o conceito preferido por pesquisadores das ciências sociais que buscam elencar os traços assinaladores de especificidade que individualizam um povo. Na academia, tais preocupações remontam aos estudos da virada do séc. XIX ao XX sobre "caráter nacional”, os quais buscavam, frequentemente a partir de referenciais racistas e eurocêntricos, 
identificar características comportamentais, fenotípicas e ambientais que explicassem as diferenças entre as gentes (LEITE, 1992; ORTIZ, 2013). Contemporaneamente, os estudos sobre identidade nacional, despojados do legado essencialista, se concentram nas narrativas, símbolos e ideias que vieram, no decurso de um processo histórico, a compor o estoque ideacional a partir do qual se articulam as definições do que vem a ser determinada nação (HALL, 2006).

Assim, obras sobre a identidade nacional brasileira perguntam, na verdade, “quem são os brasileiros?”, podendo recorrer a elementos como formação histórica, cultura e outros fatores para explicar por que os membros dessa sociedade são caracterizados por certos traços, valores e práticas, ou ainda tentar desvelar como tais referenciais são mobilizados ao longo do tempo e por quem. São, portanto, análises cuja unidade principal de análise é a população que se identifica como pertencente àquela sociedade nacional. Por ter uma preocupação em fazer a exegese do que seria "o nacional”, tornou-se um conceito que é tomado de empréstimo com liberalidade por diferentes perspectivas teóricas e subcampos das ciências sociais, desde a sociologia até a literatura (ANDERSON, 1991; LEITE, 1992; DE CILLIA; REISIGL; WODAK, 1999).

Já o conceito de identidade internacional remete a como um Estado soberano veio a desenvolver sua identidade, papéis e interesses junto aos demais Estados no sistema global. Trata-se, portanto, de uma preocupação analítica ligeiramente distinta, pois sua unidade de análise não é uma população ou uma coletividade humana, mas o Estado nacional. Esse é entendido como um ator inserido em um tipo de sociedade, a sociedade internacional, e que, portanto, deriva seu self dessa convivência intersubjetiva (WENDT, 1992). Pesquisadores operando com tal conceito se focam em observar como a identidade de um país afirma-se no plano externo, e como as próprias relações externas são um vetor através do qual essa identidade é moldada. Diferentemente do conceito de identidade nacional, que é apropriado facilmente por várias disciplinas, identidade internacional é um conceito mais firmemente enraizado em RI e, em especial, dentro da tradição construtivista.

Em resumo, podemos definir que identidade nacional é um conceito recepcionado por várias disciplinas e vertentes teóricas, voltado aos processos históricos e elementos simbólicos que singularizam os membros de uma comunidade nacional. Identidade internacional, por sua vez, é um conceito mais restrito ao campo das RI e, particularmente, ao construtivismo. Ele diz respeito às teorias ou imagens que os atores do sistema internacional mantêm uns sobre os outros a partir 
de um repertório simbólico formado interativa e intersubjetivamente. No entanto, é importante ter em mente que a fronteira entre ambos os conceitos é porosa, visto que, primeiramente, a dualidade entre o doméstico e o internacional não é sem ambiguidade, e a interpretação do que caracteriza um Estado forçosamente terá de recorrer a ângulos internos e externos, aos processos que incidem sobre a população e às interações interestatais.

\section{Identidades e interesses na perspectiva construtivista}

O construtivismo inaugurou um lugar de destaque para o conceito de identidade e interesses. Diferentemente das teorias neorrealista e neoliberal das RI, que os veem como exógenos e apriorísticos, o construtivismo defende que eles são endógena e intersubjetivamente gerados. Identidades são expectativas estabelecidas a respeito de si, que se formam conforme o sujeito participa de sentidos coletivos (WENDT, 1992). São fenômenos sociais e relacionais, sendo, portanto, "contingentes, dependentes da interação do ator com outros e posição dentro de um contexto institucional" (BARNETT, 1999, p. 9). Hopf (1998) destaca que uma consequência de as identidades serem fatos sociais é que o ator não é o árbitro final do que ele próprio significa para os outros; a estrutura intersubjetiva de sentidos é que o é.

Outra característica importante é o valor dado à dimensão ideacional. Não são apenas as capacidades materiais de um Estado que determinam seu comportamento, mas as crenças mantidas por ele e por seus pares. Assim, na leitura de Wendt $(1987,1992)$, Adler (1997) e Guzzini (2000), o construtivismo está em uma posição mediana entre a visão racionalista/objetivista e a visão idealista/reflexivista, por defender que a realidade é uma construção social em aberto, mas que possui um lastro em bases materiais.

O construtivismo também está na via média entre o indivíduo e a estrutura, pois nega a ambos a antecedência ontológica, defendendo que agente e estrutura são mutuamente constituídos² (WENDT, 1987, 1992; ADLER, 1997; HOPF, 1998). Será através da prática que um ator buscará materializar sua visão de mundo, e será o conjunto regente de práticas que delimitará os limites da ação aceitável, legítima ou compreensível.

2 Premissa herdada da teoria da estruturação de Anthony Giddens (1984). 
Em conclusão, frisamos que o construtivismo não é uma teoria homogênea: abriga correntes convencionais/positivistas e críticas/pós-estruturalistas (HOPF, 1998). No que tange o conceito de identidade, sua divergência principia em nível ontológico, pois um dos atores tomados como dado para os convencionais, o Estado soberano, é um construto controverso na leitura pós-estruturalista (NEUMANN, 1996). Ademais, em ambos os polos há variação sobre quais fatores são mais relevantes na criação identitária: se internos ou externos, estatais ou não estatais (FINNEMORE; SIKKINK, 2001).

\section{Síntese do conceito de identidade: sua natureza, elaboração e atores}

A perspectiva construtivista traz consigo implicações importantes sobre: (i) a natureza da identidade internacional de um país, (ii) sua forma de elaboração, e (iii) os atores que operam nesse processo. Primeiramente, destaca-se (i) a natureza narrativa e prática das identidades. A identidade internacional é simultaneamente uma narrativa e uma prática. Embora possa ser forjada de forma deliberada, uma identidade não é de todo artificial, dado que precisa referenciar-se à cultura ou a algum conhecimento compartilhado pela população envolvida para que seja aceita (MARCUSSEN et al, 1999; HALL, 2006). A identidade, contudo, não reside apenas em plano conceitual, pois ganha materialidade em loci específicos: símbolos, políticas, diplomacia e outras práticas que concretizam uma realidade intersubjetiva. Pode-se conceber então que o processo de formação da identidade internacional possui etapas narrativas, ou reflexivas, em que os atores deliberam sobre o conteúdo e significado de sua identidade, seguidas de etapas práticas ou performativas, em que esse entendimento é materializado através das ações.

Essa divisão em dois estágios está presente de formas variadas na literatura. Baseando-se no dialogismo bakhtiniano, Guillaume (2002) aponta que a formação da identidade nacional é um processo em dois tempos, composto por uma etapa simbólica e uma prática. Na primeira, estabelece-se o repertório com base no qual o self nacional é delimitado, enquanto que na segunda os valores presentes nesse repertório são materializados. Abdelal et al. (2006) decompõem a identidade em duas dimensões: seu conteúdo e a contestação. Em outras palavras, mesmo que as práticas sociais cristalizem um entendimento do que significa esposar determinada identidade (i.e.: seu conteúdo), eventualmente os atores propõem novos entendimentos e interpretações, contestando assim o conteúdo vigente. 
Em segundo lugar, (ii) identidades são elaboradas de forma interdiscursiva. "Interdiscursividade" é um conceito originário da Análise do Discurso, campo do saber que compartilha importantes pressupostos epistemológicos construtivistas ${ }^{3}$ e pode, portanto, ser produtivamente visitado para essa investigação. Entende-se interdiscursividade como uma qualidade constitutiva do discurso que diz respeito às formas como um discurso aponta a outros dizeres que o entornam ou precedem. Charaudeau e Maingueneau (2008, p. 286) o definem como "o conjunto de unidades discursivas [...] com os quais um discurso particular entra em relação implícita ou explícita" [grifo no original]. O inter-relacionamento entre diferentes discursos afeta, de maneira constitutiva, como um dizer consegue produzir sentido. Orlandi (2007, p. 31) afirma que o interdiscurso "disponibiliza dizeres que afetam o modo como o sujeito significa em uma situação discursiva dada”, de modo que a compreensão de sentidos atuais requer a análise dos discursos que os precederam e como suas significações se cristalizaram.

No construtivismo, argumenta-se que a realidade social é construída por uma dimensão material e uma simbólica. Essa última comporta um repertório cognitivo comum que garante a inteligibilidade das práticas sociais (ADLER, 1997; BARNETT, 1999; RISSE, 2000). A identidade internacional de um país, entendida em termos de ideias compartilhadas, também observa essa lógica. Novas narrativas precisarão recorrer a um inventário comum de eventos, línguas, histórias e práticas da nação (ainda que para ressignificá-lo) se quiserem que suas novas leituras sejam aceitas (BARNETT, 1999; GUILLAUME, 2002; MARCUSSEN et al., 1999; HALL, 2006).

Identidades podem se atualizar; por esse motivo, estão inseridas num diálogo entre diferentes textos, que mobiliza o passado (imemorial e recente) e o presente, pois a identidade nacional precisa se basear em elementos de uma história profunda e amplamente difundida, responder a uma formulação anterior e esgotada, e dialogar com articulações concorrentes. Em outras palavras, definir, em dado momento, o que "somos" requer um esforço interpretativo do que

3 As aproximações entre AD e construtivismo dizem respeito à importância da alteridade para a constituição da identidade e ao papel do interdiscurso e da memória em referenciar um repertório comum que permita aos dizeres atuais fazerem sentidos. No entanto, a relação entre agente e estrutura é teorizada de forma distinta por cada abordagem: o construtivismo (positivista em especial) prevê um sujeito socialmente constituído, mas ainda assim capaz de ação estratégica que inove a estrutura, enquanto a AD teoriza um sujeito mais sobredeterminado pela estrutura (POSSENTI, 2009). Apesar da dissonância ontológica, a conjugação das duas perspectivas é plausível, dado que em ambas encontramos uma mesma preocupação quanto à tensão entre estabilização e mudança semântica. 
"fomos", do que "seremos", do que "os outros são" e assim sucessivamente. A natureza narrativa e prática das identidades e sua interdiscursividade estão inter-relacionadas, como explica Barnett (1999, p. 14):

De modo geral, a narrativa da identidade nacional fornece um entendimento do passado, presente e futuro, eventos são simbólicos e constitutivos daquela identidade, e estão subjetivamente conectados a ela, e uma construção particular do passado será o cordão umbilical com o presente e o futuro. Essa narrativa da identidade nacional não é dada mas é, ao invés, uma construção social, e atores irão reconstruir o passado conforme eles debatem o futuro, e conforme eles agem em direção ao futuro eles tenderão a (re)lembrar o passado. $^{4}$

Por fim, (iii) seu caráter plural. A identidade de um país é fruto da ação de uma multiplicidade de atores. Fundamentalmente, o delineamento do self se dá de forma dialética na presença do Outro. No momento de sua elaboração, há atores que competem para estabelecer novos paradigmas, e sua validação depende da reação de outros agentes cuja opinião importa. A existência dessa diversidade de atores abre o espaço para o papel do poder e das assimetrias no estabelecimento de uma narrativa vencedora, tirando das mãos do ator unitário a responsabilidade pelo significado (HOPF, 1998; GUILLAUME, 2002). Com essas considerações sobre a natureza da identidade internacional de um país, sua forma de elaboração, e sobre os atores que nela operam, será agora analisado o caso específico do Brasil.

\section{As dimensões da identidade internacional do Brasil}

Como exposto anteriormente, identidades são narrativas e performáticas, articulam-se em torno de um repertório comum e são desenvolvidas por uma pluralidade de atores. Esta seção apontará diferentes elementos geográficos, políticos, econômicos e culturais que foram, historicamente, mobilizados para confeccionar a identidade internacional do Brasil, buscando acompanhar, para cada um, como operaram essas três facetas do nosso framework conceitual. Em

4 No original: "In general, the narrative of the national identity provides an understanding of the past, present and future, events are symbolic and constitutive of, and subjectively linked to, that identity, and a particular construction of the past will be the umbilical cord to the present and the future. This narrative of the national identity is not given but rather is a social construct, and actors will reconstruct the past as they debate the future, and as they act towards the future they are likely to (re)remember the past" (BARNETT, 1999, p. 14) 
especial, será dada ênfase ao elemento exterior nessa caracterização, buscando assim compreender a influência do internacional nas "forças profundas" ou "fatores de persistência” que moldaram a identidade do Brasil (LAFER, 2009).

\section{Dimensão socioeconômica: o imperativo do desenvolvimento no país de contrastes}

Lafer $(2009$, p. 116) aponta que o desenvolvimento econômico do espaço nacional é um objetivo almejado igualmente pelo Estado e população, tornandose a força profunda que mais marcou e hoje rege a identidade brasileira, de modo que a própria "questão nacional" se confunde com a "questão social". Magnoli et al. (2000, p. 35) também elencam o desenvolvimento no topo da lista dos valores fundacionais "de quem somos e o que aspiramos como coletividade", sendo esse “talvez o consenso mais permanente da história do Brasil” perseguido de várias formas desde o pós-2 ${ }^{\text {a }}$ Guerra.

O norte do desenvolvimento recebeu tratamento teórico por diversos atores. Domesticamente, destaca-se o Instituto Superior de Estudos Brasileiros (ISEB) criado em 1955, cujos intelectuais, notadamente Hélio Jaguaribe, avançavam o "nacionalismo desenvolvimentista". Essa narrativa condensa desenvolvimento econômico e afirmação da identidade nacional sob um mesmo signo, dá ênfase à capacidade planejadora de um Estado "funcional”, e se apresenta como ideologia própria às "novas forças" sociais e econômicas". Mesmo com a mudança de regime no Brasil em 1964, a palavra "desenvolvimento" figura, infalivelmente, na doutrina elaborada pela Escola Superior de Guerra (ESG), "segurança e desenvolvimento", que retém também a ênfase no planejamento estatal (IANNI, 2004). Regionalmente, a Comissão Econômica para a América Latina (CEPAL) também fez uma longeva contribuição teórica sobre o posicionamento das economias periféricas no mundo.

Para além do narrativo, o desenvolvimentismo tomou corpo no domínio das práticas, a partir dos anos 1950, sobretudo na criação de empresas e agências estatais em setores estratégicos: Petrobrás, Banco Nacional de Desenvolvimento Econômico (BNDE), Banco do Nordeste (BND), Sudene, e outras.

\footnotetext{
5 "A tese central do nacionalismo desenvolvimentista é a de que a promoção do desenvolvimento econômico e a consolidação da nacionalidade constituem dois aspectos correlatos do mesmo processo emancipatório [...] é a ideologia típica das forças novas, que se acham identificadas com o processo de decolagem econômica do Brasil” (JAGUARIBE, 1958, p. 208-209 apud IANNI, 2004, p. 258).
} 
Segundo Ortiz (2013), não apenas para o Brasil, mas para o resto da América Latina e do mundo subdesenvolvido, o tema da identidade é recorrente por haver uma obsessão com o tema do nacional. Em países periféricos, cuja entrada na modernidade sempre se apresenta parcial, sua própria completude enquanto Estado-nação se apresenta incerta, contingente e carente de resolução.

A busca da identidade brasileira esbarra numa contradição estrutural, ela se faz na periferia, a concepção de uma temporalidade linear lhe é sempre desfavorável. Qual seria o lugar do Brasil na esfera internacional? A pergunta necessariamente conduz a um dilema: num país no qual a modernidade é incompleta, a nação somente existiria num tempo projetado à frente. Dito de outra maneira, o presente é o problema, com seus obstáculos e adversidades ele denega ao conceito o estatuto almejado. (ORTIZ, 2013, p. 616)

Há reflexos internos e externos da dimensão econômica na compreensão do que é o Brasil no mundo. Internamente, ela se manifesta nos baixos indicadores de desenvolvimento, desigualdades sociais e demais fatores que reiteram o atraso econômico e social do país. Tal condição, a chamada questão social, remete a outro conceito pelo qual o Brasil se identifica: o do país de contrastes, que tem dentro de suas fronteiras realidades do Primeiro e do Terceiro Mundo. Tal discrepância é compartilhada por outros países da América Latina e os situa num mesmo endereço peculiar do cenário internacional: o "outro Ocidente: mais pobre, mais enigmático” (MERQUIOR, 1990, p. 87) ou “Extremo-Ocidente” (ROUQUIÉ, 1987).

Externamente, o primado do desenvolvimento tem sido o norte das ações da Política Externa Brasileira (PEB) enquanto política pública. A diplomacia brasileira buscou o objetivo do desenvolvimento agindo em duas linhas mestras a partir da década de 1930: a preservação de um espaço de autonomia nacional e a identificação de recursos externos que pudessem ser mobilizados para atender ao imperativo do desenvolvimento (LAFER, 2009). Cervo (2003) argumenta que o paradigma do Estado desenvolvimentista que guiou a política externa a partir dessa época era caracterizado por: uma nova compreensão da parte das elites políticas acerca da crescente complexidade da sociedade brasileira; o desenvolvimento como norte da política externa; e um realismo de conduta. Embora houvesse visões concorrentes tanto entre as elites quanto na opinião pública, sobretudo acerca da opção pela associação com potências capitalistas ou pelo desenvolvimento autônomo, a acomodação entre ambas garantiu a longevidade do modelo. Foi substituído pelo paradigma do Estado normal nos 
anos 1990 sob a égide do consenso de Washington e das reformas neoliberais em toda a América Latina. Os anos 2000 viram o retorno do Estado como importante indutor do crescimento no chamado paradigma do "Estado logístico" (CERVO, 2003) ou "neodesenvolvimentismo liberal" (BAN, 2013).

Assim, o desenvolvimento é central na formação identitária por praticamente confundir-se com a efetivação do Brasil enquanto Estado moderno de fato. Sucessivas gerações de atores políticos, de distintas orientações ideológicas, mantiveram a narrativa do desenvolvimento, oscilando apenas quanto aos meios de alcançá-lo (práticas) e sentidos agregados a ele (interdiscurso).

\section{Dimensão política: autônomos ou excluídos?}

A literatura aponta a autonomia como um objetivo duradouro da PEB, tendo sido perseguida de diferentes formas durante a história do país. "Autonomia", nesse caso, não se resume à faculdade elementar que se atribui a todos os Estados soberanos em um sistema internacional anárquico. Como detalham Vigevani e Cepaluni (2011), na ótica dos países periféricos, para os quais os constrangimentos hierárquicos do sistema internacional são mais salientes, tal conceito está mais atrelado a um projeto político de formulação e implementação autônoma da política externa do que a um preceito jurídico.

Cervo (2008, p. 31), que dá a essa faculdade o nome mais preciso de "independência de inserção internacional”, entende que o Brasil pertence a um grupo peculiar de países "cuja vocação os impele a perseguir um modo próprio de inserção internacional”, pressupondo para tanto uma visão de mundo própria. Há longa data, o Itamaraty preocupa-se em não restringir suas opções. Nesse registro, a relação Brasil-EUA tem sido usada como um indicador do grau de autonomia ou alinhamento nacional. Durante a Guerra Fria, confrontado com a principal dicotomia política da ordem bipolar (Ocidente capitalista x Leste comunista), o Brasil professou uma filiação ocidental. Porém, dada a plasticidade do conceito de "Ocidente" 6 , o país trafegou por vários matizes de ocidentalidade, segundo as conjunturas e interesses. Cada fase contou com narrativas, práticas e atores próprios. O primeiro modelo foi o “ocidental puro", marcado por adesão irrestrita a valores ocidentais e aliança estratégica com os EUA. Teve sua operação mais enérgica no governo Dutra (1946-1951), que combateu o comunismo

6 Sobre a polissemia do conceito de “Ocidente”, ver breve resumo em Steiner, Medeiros e Lima (2014). 
vigorosamente no plano interno (decretou ilegalidade do Partido Comunista) e externo (cortou relações com a União Soviética), e aceitou a liderança dos EUA nos organismos multilaterais. Com o golpe de 1964, o "ocidental puro" foi ressuscitado e teve seu momento paradigmático com o envio de tropas à República Dominicana em 1965. Pouco após, contudo, esse modelo começa a se desfazer: o decreto do AI-5, a oposição ao Tratado de Não-Proliferação Nuclear (TNP) e opacidade face aos direitos humanos mostram que, com o período autoritário, o modelo passaria por transformações.

O modelo "ocidental qualificado" reflete a autonomização brasileira e encontrou expressão mesmo antes do "ocidental puro". Ele ocorreu no segundo governo Vargas e no governo de Juscelino Kubistchek. Persiste a adesão à democracia, o repúdio ao socialismo e a proximidade política dos EUA. Todavia, há um distanciamento calculado em tópicos pontuais (Vargas: nacionalização do petróleo; JK: divergências com o Fundo Monetário Internacional [FMI] e lançamento da Operação Pan-Americana).

Por fim, o "ocidental autônomo" é considerado por Fonseca Jr. (1998, p. 272) a "mais articulada e completa tentativa de desenhar, de forma própria, uma identidade internacional para o país”. Ele se deu nos governos Jânio e Goulart e, posteriormente, nos anos 1970. Há uma diferença na ordem dos valores, já que no primeiro momento somos uma democracia e, no segundo, um regime autoritário. O autor afirma que nesse segundo momento o "ocidental" passa a ter conotações de democratização das organizações internacionais - ainda que advogada por um país, naquele momento, não democrático.

No plano econômico, a posição autônoma também é reflexo da maior complexidade de interesses do Brasil em rápida industrialização. Esses afastamentos nos planos político e econômico revelam que o país busca criar, no marco do Ocidente, uma identidade própria, à parte das lideranças do bloco. Sob o chanceler Saraiva Guerreiro, essa revisão estratégica das relações com as potências ocidentais e abertura a novos parceiros segundo as necessidades da economia ganharam contornos conceituais e normativos. O universalismo foi então levantado como uma vocação da nação brasileira no plano exterior (FERREIRA, 2009).

Trazendo a análise para os últimos 30 anos, Vigevani e Cepaluni (2007) identificam três momentos da PEB. Cada um desses estágios é marcado por uma interpretação - e, por conseguinte, interdiscursos - do que vinha a ser a autonomia. A "autonomia pela distância" se caracterizou pela preservação da soberania do Estado, investimento no desenvolvimento autárquico, e rejeição 
das agendas automáticas das grandes potências. Com a redemocratização, o país perseguiu a "autonomia pela participação", através da adesão aos regimes internacionais liberais com objetivo de influenciá-los através das perspectivas nacionais. Por fim, os autores identificam que a partir do governo Lula se buscou a "autonomia pela diversificação": adesão às normas internacionais por meio das alianças regionais, alinhamentos Sul-Sul e contato com novos parceiros para redução de assimetrias e aumento do poder de barganha. Outras "grandes interpretações" da trajetória da PEB também tendem a repetir esse padrão trifásico, porém com ênfases e marcos variantes?

Pode-se concluir que a estrada para a autonomia teve seus picos e vales de aproximação com países hegemônicos, devido a causas externas ( $2^{\text {a }}$ Guerra Mundial e a Guerra Fria) e internas (golpe militar em 1964, crise financeira e reformas neoliberais nos anos 1990). Contudo, nos últimos 70 anos o país mostrou um padrão de afastar-se de alinhamentos automáticos conforme lhe permitia sua prosperidade econômica (AMORIM NETO, 2011). Assim, o desenvolvimento econômico e a autonomia política podem ser vistos como dois lados de uma mesma moeda.

Como consequência dessa inter-relação entre as duas dimensões, instantes de fracasso econômico nacional também tendem a produzir crises de pertencimento político no Estado brasileiro. Escrevendo no final dos anos 1990, uma década marcada pela estagnação econômica e diminutas perspectivas, Abdenur (1997, p. 32) falou de um "sentimento de exclusão" que acometia o país, que estava "sempre mais à margem das principais tendências políticas e econômicas do cenário internacional”.

Por outro lado, o Brasil, por ser uma potência média, portanto nem totalmente pertencente ao rol das grandes potências nem das pequenas, possui uma habilidade de intermediação que tem sido repetidamente valorizada pela sua diplomacia. A ordem internacional contemporânea é estratificada, marcada por assimetrias importantes entre os Estados. Lafer (2009) afirma que o Brasil é um país com "dupla inserção", pois devido à sua complexidade possui diversas agendas, que o colocam em diálogo tanto com os países centrais quanto com os periféricos ${ }^{8}$.

7 Vide Amorim Neto (2011) para um resumo.

8 “[O] Brasil é um país de contrastes, com múltiplas dimensões. Por isso participa naturalmente de numerosas esferas de convívio internacional. É um país ocidental no campo dos valores, em função de sua formação histórica, realidade que não excluía a sua inserção entre os países do Terceiro Mundo, com os quais tinha posições afins no quadro das ações específicas voltadas para o desenvolvimento, que respondiam ao interesse nacional” (LAFER, 2009, p. 41). 
Para Arbilla (2009, p. 359), tal conjugação conceitual dos papéis de "mediador" e "nação de contrastes" permitiu ao Brasil aproximar-se de países desenvolvidos sem comprometer seus interesses políticos e econômicos com o mundo em desenvolvimento. As credenciais dessa atitude estariam presentes no interior da própria sociedade brasileira, que também abriga assimetrias socioeconômicas análogas. A era Lula representou possivelmente uma cristalização dessa imagem, tendo o país um presidente bem-vindo tanto em Porto Alegre quanto em Davos (ROUQUIÉ, 2006).

Em síntese, a dimensão política da identidade internacional brasileira captura o posicionamento de Brasília face ao mundo ocidental e as diferentes alternativas até então mobilizadas para melhorar sua inserção internacional. Trata-se de uma dimensão suscetível à revisão e contestação haja vista que reflete, em alguma medida, clivagens ideológicas duradouras que perpassam o Itamaraty ${ }^{9}$, bem como a própria sociedade brasileira, sobre qual tipo de alinhamento é preferível para o Brasil alcançar seus objetivos: se com o Primeiro Mundo capitalista e ocidental ou com o Sul Global e suas orientações contra-hegemônicas.

\section{Dimensão étnico-cultural: raça, cultura e comparações}

Demograficamente, a miscigenação é um dos elementos definidores do Brasil. Como apontou Darcy Ribeiro (2006), nosso povoamento foi original pelo fato de que as matrizes raciais para cá transladadas efetivamente geraram um "povo novo”. Regionalmente, isso diferenciou o Brasil dos países andinos, cujo povo herdeiro de civilizações pré-colombianas profundas - viveu dificuldades maiores com a dualidade cultural e assimilação europeia. Da mesma forma, o diferenciou dos vizinhos platinos que, ao invés de povos "testemunhas" abrigaram povos europeus "transplantados".

O fator étnico configura-se como "profundo" por ter ocorrido na gênese do país, e como "persistente" por perpetuar-se, por exemplo, com as levas de trabalhadores europeus, asiáticos e árabes no séc. XX. Contudo, é interessante destacar que o significado, interpretação e valor da matriz racial brasileira variaram historicamente. A releitura de um mesmo fator histórico ou cultural é parte do

9 Ver a discussão em Saraiva (2010) sobre as correntes institucionalista/pragmática e a autonomista/nacionalista no Ministério. 
processo de atualização identitária comum a todos os Estados (vide BARNETT, 1999), porém, no caso brasileiro, também chama atenção o peso que os discursos internacionais tiveram sobre esse procedimento.

Dante Moreira Leite (1992), ao analisar a influência histórica do pensamento estrangeiro sobre a autoimagem do Brasil, conclui que, excetuados os instantes românticos e nacionalistas, as ideias de atraso e marginalidade há muito acompanham o país tropical e tendem a buscar explicações em elementos raciais ou culturais. A raiz do subdesenvolvimento era atrelada ora à raça mestiça (por exemplo, em pensadores como Sílvio Romero e outros influenciados pelas teorias racistas que emanavam da Europa no séc. XIX), ora à cultura ibérica pouco industriosa de sua gente (como indicava Manuel Bonfim, e em alguma medida também Sérgio Buarque de Holanda, em tempos mais recentes). Em virtude desses traços, o país estaria sempre defasado em comparação, respectivamente, com a Europa branca (no séc. XIX) ou os norte-americanos protestantes (no séc. XX).

É relevante destacar que em ambos os casos temos um exercício de comparação civilizacional. Vê-se que, primeiramente, o Brasil é comparado à Europa pelo prisma da inferioridade racial e cultural. Porém, conforme outra nação jovem emerge como potência global, o foco volta-se, primordialmente, à díade entre religião e cultura, ou seja, humores e costumes da população que têm efeitos sobre o trabalho e a produção. O agente do atraso brasileiro, assim, continuaria sendo a população, embora não mais pela raça, mas por sua cultura. Como outros países periféricos, o Brasil também buscava seu referencial civilizacional no exterior e, nesse processo, localizava o Outro inferior em suas próprias fronteiras ${ }^{10}$. Por essa razão, para Ortiz (2013), a temática do estrangeiro, ou mais especificamente o da imitação desse, é recorrente nos debates sobre a identidade brasileira. Almejando realizar os ideais da civilização ocidental, o Outro externo será alvo de amor ou ódio dos observadores brasileiros (MERQUIOR, 1990, p. 86).

10 Jancsó e Pimenta (2000, p. 174) argumentam que o Brasil recém-independente não lograva identificar seu "corpo social” com a "nação”. Num Brasil que já não se identificava com Portugal, mas tampouco se reconhecia como um só povo, dadas as diferenças regionais, a identidade nacional brasileira definiu-se em oposição ao Outro interno, o escravo. Quanto a esse processo de produção de alteridade, é instrutiva a leitura de Schaebler (2004). Ela afirma que a civilização ocidental, se crendo portadora de uma história universal, interpreta outros povos como um Outro inferior, pertencente a um estágio retrógrado da humanidade. Países periféricos desejosos por se tornarem sociedades modernas passam, então, a identificar esse Outro (othering) não mais em outros povos, mas dentro de suas próprias fronteiras. Trata-se de um Outro interno, que reúne todas as características então interpretadas como retrógradas e não civilizadas. 
Tais leituras foram contestadas ao longo do séc. XX através de pensadores que reinterpretaram a miscigenação de forma positiva (Gilberto Freyre ${ }^{11}$ ) ou mais crítica (Darcy Ribeiro), ou atribuíram os atrasos brasileiros a processos históricos e econômicos - e portanto passíveis de superação (Caio Prado Júnior). De Freyre em diante, as narrativas raciológicas dão lugar a uma apreciação da mestiçagem, que encontra eco mesmo em nível político-institucional (ROUQUIÉ, 2006, p. 63)

O discurso contemporâneo da diplomacia brasileira não falha em louvar a miscigenação, e dela derivar virtudes que possam ser imputadas à política externa. Lafer (2009) afirma que o país é conhecido por seu pluralismo, multietnicidade, abertura à integração cultural e ao sincretismo da diversidade; Abdenur (1997) afirma que pluralidade social e étnica habilita o Brasil a ser interlocutor junto a públicos variados. Etnicamente, sua matriz miscigenada o gabarita para o diálogo com diferentes povos ${ }^{12}$. Socialmente, a coexistência de índices de desenvolvimento humano escandinavos e subsaarianos no seu território também reforça sua capacidade de diálogo com os países desenvolvidos e subdesenvolvidos. Mesquita e Medeiros (2016) identificam um apelo recorrente a "credenciais multiculturais" no discurso presidencial e da chancelaria para legitimar e naturalizar a aproximação com novos parceiros na África, Ásia e Oriente Médio.

Ortiz (2013) acrescenta a esse debate a observação que, se as interpretações sobre a identidade brasileira calcadas na raça e cultura tinham o horizonte da totalidade e unidade nacional ao longo do séc. XX, o advento da globalização problematiza essa construção unitária, já que fontes identitárias múltiplas desafiam o monopólio do Estado-nação enquanto principal catalisador de pertencimentos. Não obstante, o autor crê que esse pluralismo centrífugo não

11 “Com a revolução de 30, a industrialização e a modernização do país, a ideia de mestiçagem é ressignificada, seu aspecto negativo transmuta-se em positivo. Neste sentido, a obra de Gilberto Freyre é importante, ela confere aos brasileiros uma carteira de identidade. Como bem aponta Elide Rugai Bastos, para Freyre o ideal da mestiçagem encerra a capacidade de se conciliar as contradições: políticas, culturais, sociais e econômicas. O mestiço é o ideal harmônico no qual se espelha o 'segredo do sucesso do Brasil'. Esta mudança de sinais, do negativo para o positivo (nos primeiros escritos de Monteiro Lobato, o Jeca Tatu, na sua indolência e preguiça, é a metáfora do país), possibilita uma releitura da história, do desenvolvimento e da modernização, virtudes antes incompatíveis com o espírito nacional, e agora viáveis e factíveis mediante a atuação coordenada do Estado. É neste contexto que os novos símbolos de identidade - mulata e samba - se consolidam, liberados da canga das interpretações raciológicas, eram marcados pela mácula de inferioridade, são alçados à categoria de brasilidade" (ORTIZ, 2013, p. 615).

12 Embora as virtudes da miscigenação sejam imputadas à diplomacia brasileira, convém destacar que o corpo diplomático em si permanece com baixa diversidade racial: em dez anos (2002-2012) de ação afirmativa para ingresso de mais negros na academia diplomática brasileira, menos de $3 \%$ dos novos diplomatas eram afrodescendentes (FELLET, 2012). 
significa que representações clássicas ou ancestrais da brasilidade tenham se tornado anacrônicas. As representações da brasilidade passam a ser "um estoque de símbolos. A corrosão do tempo não os atinge, eles fazem parte de uma coleção brasiliana que pode ser ativada de acordo com as estratégias de quem os utiliza [...] a identidade é o resultado do arranjo das peças depositadas nas camadas geológicas da tradição nacional” (ORTIZ, 2013, p. 631,633).

\section{Dimensão continental: a escala colossal e relações regionais}

Uma outra força profunda que define o Brasil é seu território e região. A escala do "Gigante do Cone Sul" o coloca no rol dos países continentais, juntamente com EUA, Rússia, China e Índia. Tal dimensão também valoriza o papel da diplomacia brasileira no estabelecimento da identidade internacional do país, já que muito se credita ao trabalho do Barão de Rio Branco na consolidação jurídica das fronteiras no séc. XIX. O amplo território inspira duas outras ideias nativistas importantes. Primeiramente, a ideia de grandeza física e, em segundo, a de unidade, preservada apesar da vastidão do país e de sua heterogeneidade. Na elaboração de Corrêa (2000, p. 27), esses são dois vértices de uma "trindade do sentimento nacional brasileiro", encimados por uma "crença no futuro", isto é, uma expectativa que a grandeza herdada e a unidade mantida projetariam enfim o país, no tempo futuro, ao patamar de suas aspirações de preeminência e autonomia. Como sintetiza Rouquié (2006, p. 19), “a extensão geográfica é o fundamento cultural da ação. A grandeza supõe grandiosidade"13.

Nessa dimensão, o Brasil se diferencia de seus vizinhos regionais. Enquanto conseguimos preservar a unidade territorial e linguística, os demais países latinoamericanos se fragmentaram após a independência ${ }^{14}$. Politicamente, o Brasil também teve uma experiência particular, pois chegou a abrigar a metrópole, nos últimos estágios de sua colonização. Seu processo de independência também foi consideravelmente menos traumático que o dos vizinhos, desdobrando-se sem a

13 No original: "L'étendue géographique est le fondement culturel de l'action. La grosseur suppose la grandeur".

14 Um dos motivos apontados pela literatura é a maior homogeneidade das elites brasileiras. Enquanto que as colônias hispânicas na América possuíam universidades desde o séc. 16, fermentando assim uma vida intelectual autônoma em cada localidade, as elites dirigentes brasileiras todas iam a Coimbra para sua formação (ROUQUIÉ, 2006, p. 21). "Las universidades de la España colonial, hicieron posible el surgimiento de numerosas élites educadas con muy poco contacto entre ellas y con la 'Madre Patria'. Cuando comenzó la lucha por la independencia, un bajo porcentaje tenía la visión más amplia de la 'Gran América'. Al mismo tiempo, en la colonia portuguesa, había una sola élite, con la misma educación y experiencia” (PEREYRA-DOVAL, 2013, p. 54). 
figura dos "libertadores" e buscando, não a ruptura, mas a continuidade do modelo de Estado dinástico europeu (SANTOS, 2010). Assim, uma vez independente, o Brasil tornou-se uma monarquia lusófona em meio a repúblicas hispânicas, passando boa parte dos seus primeiros anos voltada ao Velho Mundo. Santos (2014, p. 26) explica que durante o Império

[o] discurso oficial sobre a identidade brasileira procurava apresentá-la como um império que, ainda que tropical e distante, se assemelharia mais às monarquias europeias e seria, assim, essencialmente distinto de seus vizinhos. Na clivagem metafórica entre América e Europa, o Brasil dos oitocentos alinhava-se com as monarquias. Entendia-se civilizado e, portanto, “europeu”, em contraste com as turbulentas repúblicas vizinhas.

Por essa razão, Sombra Saraiva (1995) afirma que, pela maior parte do séc. XIX, o Brasil deu as costas para os demais países da América Latina, que também o viam com suspeita. O sentimento era recíproco. O restante da América Latina republicana também via com suspeita o gigantesco império ao lado e sua afinidade com os dominadores do Velho Continente (PEREYRA-DOVAL; ROMERO, 2013)15.

Essa tendência começou a ser revertida na República Velha, quando a política externa do país abraçou uma identidade americana seguindo duas linhas mestras traçadas pelo Barão de Rio Branco: uma “aliança não escrita” com os EUA e uma ativa política regional, voltada sobretudo ao Cone Sul (SANTOS, 2010). A PEB buscava assim, por um lado, reconhecer a supremacia dos EUA como nova potência hemisférica, ao mesmo tempo que delineava uma região em que esperava manter-se como principal ator (TEIXEIRA, 2011). Essa busca por maior preeminência regional, contudo, rendeu poucos frutos. Caso emblemático foi a recusa de outros países sul-americanos em endossarem a candidatura brasileira a um assento permanente na Liga das Nações nos anos 1920 como um representante da região ${ }^{16}$, assim revelando a "dissonância cognitiva” entre o Brasil e seus vizinhos no que tange o papel que aquele deveria desempenhar (SANTOS, 2005, p. 8).

15 Apenas o Brasil, os EUA e o Haiti não foram convidados ao Congresso do Panamá convocado em 1824 por Bolívar, que via o Brasil como tendo um caráter fundamentalmente diferente e, pior, nutrindo ambições imperialistas sobre o Rio do Prata (BETHELL, 2009, p. 294-295).

16 Embora recomende-se cautela em traçar paralelos simples, não se pode deixar de destacar a semelhança entre esse episódio dos anos 1920 e a reticência contemporânea dos países sul-americanos em endossar a candidatura brasileira a um assento permanente no Conselho de Segurança da ONU (a Argentina, principal parceiro regional brasileiro, compõe o grupo United for Consensus, criado precisamente como contraponto ao G4 formado por Brasil, Japão, Alemanha e Índia) e demais postos de liderança em instituições internacionais. 
Em síntese, Santos (2010) argumenta que o novo papel do Brasil, sua identidade americana ativa, não foi um sinônimo de identificação com seus pares. O paradigma americanista durou até os anos 1960. A indiferença de Washington durante a Guerra Fria, aliada à crescente complexidade da economia brasileira, fizeram com que Brasília adotasse dessa década em diante um paradigma mais universalista para a política externa (AMORIM NETO, 2011).

No pós-Guerra Fria, com a aproximação do Brasil do seu até então concorrente local, a Argentina, tiveram início os processos que culminaram na criação do Mercado Comum do Sul (Mercosul), em 1991. Já nos anos 2000, com o esgotamento do paradigma neoliberal e ascensão de governos de esquerda na região, surgiu a União Sul-Americana de Nações (Unasul) como a mais abrangente de uma nova geração de iniciativas pós-liberais que privilegiam coordenação política em vez de integração comercial (TUSSIE, 2016).

Os esforços regionalistas, contudo, deixam em aberto duas perguntas importantes e inter-relacionadas. A primeira é o quão saliente é a América do Sul na definição da identidade do Brasil, e a segunda é se o país se vê (e é visto) como o líder da sua região. Ambas indagações estão imbrincadas, pois o exercício da liderança pressupõe uma autopercepção condizente e uma vontade manifesta de exercer a tarefa, seguida da aceitação pelos pares (PRYS, 2008; VAN LANGEHOVE; ZWARTIES; PAPANAGNOU, 2016).

Autores como Prado (2001), Santos (2005) e Bethell (2009) mostram, por uma perspectiva histórica, como a região (referindo-se ora à América do Sul, ora à Latina) não ocupa um lugar primordial na caracterização da identidade brasileira. Os esforços regionais dos últimos anos contribuíram para atrair a atenção brasileira à região, ao ponto que esse lançou mão de certa imaginação geográfica ao buscar demarcar a América "do Sul” como um espaço distinto da América “Latina” (TEIXEIRA, 2011). Analisando discursos diplomáticos, Jenne e Schenoni (2015) mostram que referências à primeira são muito mais frequentes para o Brasil e seus parceiros mercosulinos, enquanto Mesquita e Medeiros (2016) demonstram que a região, embora importante, é um tema menos central que a diplomacia Sul-Sul na definição identitária. Dada sua excentricidade cultural, o Brasil se mostra comparativamente menos ligado à região do que seus vizinhos mais "latinos", o que torna desafiador sua assunção de um papel de líder regional (MESQUITA, 2016; ONUKI; MOURON; URDINEZ, 2016).

Sobre a aceitação do papel de líder da América do Sul, não há consenso na literatura. Alguns autores defendem que outros Estados sul-americanos têm 
buscado contrabalancear o Brasil (FLEMES; WEHNER, 2015; BURGES, 2015), e que o Itamaraty vê a região de modo instrumental, buscando atender objetivos domésticos (SPEKTOR, 2010; VIGEVANI; CEPALUNI, 2011; LAZAROU; THEODORO, 2015). Outros creem que não cabe falar de contrabalanceamento na pacífica América do Sul (MERKE, 2015); defendem que o país assegurou uma posição de "líder do desenvolvimento" sul-americano (PINHEIRO; GAIO, 2014); ou concedem que o Brasil, conquanto não seja um líder "institucional”, vem exercendo lideranças "instrumental" e "situacional” (MOURÓN; ONUKI, 2015, p. 21)

Isso levou alguns autores a apontarem que Brasília tenderá a perseguir os seus interesses no nível global em vez de regional, como um porta-voz do Sul Global e o membro mais ocidental e pacífico dos BRICS (STEINER; MEDEIROS; LIMA, 2014). Como sintetizam Malamud e Rodriguez (2013, p. 178): “[a]o contrário de Europa, o regionalismo não tem contribuído para a mudança da identidade internacional do Brasil. O país interage fluentemente com seus vizinhos, mas não tem intenção de se fundir a eles”.

\section{Dimensão normativa: pacifismo, direito internacional e multilateralismo}

Cervo (2008) identifica traços como a solução pacífica de controvérsias, o juridicismo, o multilateralismo normativo, ação externa cooperativa e não confrontacionista, e a cordialidade no trato com os vizinhos como sendo "acumulados históricos da diplomacia brasileira" que vêm pautando sua conduta no plano externo. Lafer (2009), por sua vez, acrescenta que a busca da paz regional sempre foi um objetivo perene do país. Até hoje, o fato de o Brasil fazer fronteira com tantos países e ainda assim manter relações pacíficas com todos, sem guerras registradas nos últimos 140 anos, é um ativo valioso na caracterização do país como um ator longânime. A essa imagem aliam-se outros conceitos diplomáticos que completam a representação do Brasil no cenário internacional: a promoção do direito internacional, do multilateralismo e da resolução pacífica de conflitos - princípios listados na própria Constituição ${ }^{17}$.

17 "Art. $4^{\circ}$ A República Federativa do Brasil rege-se nas suas relações internacionais pelos seguintes princípios: I - independência nacional; II - prevalência dos direitos humanos; III - autodeterminação dos povos; IV - não-intervenção; V - igualdade entre os Estados; VI - defesa da paz; VII - solução pacífica dos conflitos; VIII - repúdio ao terrorismo e ao racismo; IX - cooperação entre os povos para o progresso da humanidade; X - concessão de asilo político" (BRASIL, Constituição Federal, 1988) 
Essa narrativa oficial é bem sintetizada por Celso Amorim (2010, p. 214), duas vezes Ministro das Relações Exteriores:

A credibilidade internacional do Brasil nasce, em grande medida, dos princípios que guiam sua política externa. Nós somos um país pacífico, que obedece o direito internacional e respeita os direitos soberanos de outros países. Nós escolhemos solucionar nossas disputas diplomaticamente - e encorajamos outros a agirem da mesma maneira. Nós vemos o multilateralismo como o principal meio para solucionar conflitos e tomar decisões internacionalmente. (AMORIM, 2010, p. 214) ${ }^{18}$

Comparado com seus atuais consortes, os BRICS, o Brasil mostra uma nítida predileção pelo soft power. Em contraste com Índia, Rússia e China, seus gastos militares são muito inferiores ${ }^{19}$, e o país tomou passos simbólicos para demonstrar seu pacifismo; por exemplo, firmou constitucionalmente o compromisso de não desenvolver armas nucleares (BRASIL, Constituição Federal, 1988, Art. 21, XXIII, a). Tal pacifismo pôde germinar livremente no Brasil, dentre outros motivos, pelo fato que o país sempre esteve afastado dos focos de tensão da política internacional (LAFER, 2009).

Santos (2010), não obstante, chama atenção para o caráter contingente dessa narrativa tão autoevidente em nossos dias. O autor localiza o início desse discurso na transição do Império para a República Velha, período de intensa atividade diplomática, capitaneada por personagens como o Barão de Rio Branco, Joaquim Nabuco e Rui Barbosa. As inclinações multilateralista e juridicista privilegiadas por esses atores proveram um referencial útil na criação de uma nova identidade internacional para o Brasil republicano, que ignorava ou mesmo refutava traços beligerantes do Brasil imperial ${ }^{20}$. Mesmo contemporaneamente, a imagem pacífica

18 No original: "Brazil's international credibility stems, to a large extent, from the principles that guide her foreign policy. We are a peaceful country, one that abides by international law and respects other countries' sovereign rights. We choose to settle our disputes diplomatically - and we encourage others to act in the same way. We see multilateralism as the primary means of solving conflicts and making decisions internationally

19 US\$ 31,5 bi em 2013, contra US\$ 188 bi (China), US\$ 87,8 (Rússia) e US\$ 47,4 bi (Índia). Fonte: Stockholm International Peace Research Institute (SIPRI) Military Expenditure Database.

20 “[A]s definições daquele momento especialmente profícuo da política externa brasileira foram consolidadas e adquiriram contornos de verdades reveladas, atemporais e indiscutíveis: a vocação pacífica e não intervencionista do Brasil, fazendo tabula rasa do passado - então muito recente —, de intervenções constantes no Prata; uma recémdescoberta (revertendo o isolacionismo do Império) vocação multilateral, tanto no contexto do pan-americanismo como nas iniciativas universais: a Segunda Conferência de Paz (Haia), a conferência de Versailles, a Liga das Nações; a confiança no Direito Internacional como arma dos países mais débeis; a defesa veemente de posições 
do Brasil é uma narrativa contingente que contorna contradições inconvenientes. Por exemplo, o fato de o país ser o quarto maior exportador de armas leves no mundo (superando mesmo Rússia e China) ${ }^{21}$.

\section{Conclusão}

O atual estudo propôs duas sínteses. A primeira foi uma compreensão mais ampla do conceito de identidade internacional, enfocando os elementos da natureza (narrativa e prática), forma de elaboração (interdiscursividade) e atores envolvidos (pluralidade) como pedras angulares de uma definição pluridisciplinar desse vernáculo. Alguns conceitos próprios da análise de discurso foram resgatados para construir essa definição.

Em seguida, aplicamos o modelo teórico ao caso brasileiro. Nossa síntese das cinco dimensões substantivas da identidade internacional do Brasil buscou reunir, de forma coerente, a multiplicidade de interpretações que há acerca do país e seu lugar no mundo. Em cada dimensão, buscou-se identificar as narrativas e práticas, interdiscursos e atores que moldaram a identidade internacional do país. Verificamos, assim, os diferentes interlocutores que propuseram modelos para caracterizar o Brasil, as práticas que consubstanciavam essas narrativas, e como os discursos em cada dimensão se inter-relacionavam uns com os outros e com um repertório comum de dizeres sobre o que é o país.

Sendo uma das preocupações do trabalho encontrar interfaces entre leituras internacionalistas e multidisciplinares, esse agrupamento buscou congregar análises de ambos os polos. Não obstante, o conteúdo das dimensões ainda é majoritariamente preenchido por autores internacionalistas, o que deixa margem para complementação posterior. Espera-se que esse quadro possa ser empregado e aperfeiçoado por outros pesquisadores, tanto de RI quanto de outros campos, lidando quer com o tema da identidade internacional, quer com o caso brasileiro em especial.

principistas como havia feito Rui Barbosa em Haia - em tensão permanente com o pragmatismo de Rio Branco em temas concretos [...]. Essas diretrizes, com a necessária carga de ambiguidade que garante a longevidade do livro sagrado de qualquer crença, consolidaram uma identidade internacional” (SANTOS, 2010, p. 190).

21 “Brasil, entre a diplomacia da paz e o destaque na exportação de armas”. El País. 1 jun. 2015. 


\section{Referências Bibliográficas}

ABDELAL, R.; et al. Identity as a Variable. Perspectives on Politics, Vol. 4, No. 4, 2006, p. 695-711. Disponível em: < ABDELAL, R.; et al. Identity as a Variable. Perspectives on Politics, > . Data de acesso: 05/11/2016.

ABDENUR, Roberto. A Política Externa Brasileira e o "Sentimento de Exclusão". In: FONSECA JR, Gélson; NABUCO DE CASTRO, Sérgio H. (Orgs.) Temas de Política Externa Brasileira II.. 2 ed. São Paulo: Paz e Terra, vol. 1, 1997. p. 31-46.

ADLER, Emanuel. Seizing the Middle Ground: Constructivism in World Politics. European Journal of International Relations. Vol. 3, No. 3, 1997, p. 319-363. Disponível em: < http://ejt.sagepub.com/content/3/3/319 > . Data de acesso: 05/11/2016.

ALESSI, Gil. Brasil, entre a diplomacia da paz e o destaque na exportação de armas. El País. 01 junho 2015. Disponível em: < http://brasil.elpais.com/brasil/2015/06/01/ politica/1433176411_490477.html > . Data de acesso: 27 junho 2016.

AMORIM NETO, Octavio. De Dutra a Lula: a condução e os determinantes da política externa brasileira. Rio de Janeiro: Elsevier, 2011.

AMORIM, Celso. Brazilian foreign policy under President Lula (2003-2010): an overview. Revista Brasileira de Política Internacional, Brasília, Vol. 53, No. Spe, 2010, p. 214240. Disponível em: < http://www.scielo.br/scielo.php?script=sci_arttext\&pid $=$ S0034-73292010000300013 $>$. Data de acesso: 05/11/2016.

ANDERSON, Benedict. Imagined Communities: Reflections on the Origin and Spread of Nationalism. London: Verso, 1991.

ARBILLA, José M. Arranjos institucionais e mudança conceitual nas políticas externas argentina e brasileira (1989-1994). Contexto internacional, Rio de Janeiro, Vol. 22, No. 2, Julho/Dezembro 2009, p. 337-385. Disponível em: < http://contextointernacional. iri.puc-rio.br/media/Arbilla_vol22n2.pdf > . Data de acesso: 05/11/2016.

BAN, Cornel. Brazil's liberal neo-developmentalism: New paradigm or edited orthodoxy? Review of International Political Economy, Vol. 19, 2012, p. 1-34. Disponível em: < http://blogs.bu.edu/cban/files/2012/12/brazil-final-proofs_oct-20n-2012.pdf > . Data de acesso: 05/11/2016.

BARNETT, Michael. Culture, Strategy and Foreign Policy Change:: Israel's Road to Oslo. European Journal of International Relations. Vol. 5, No. 5, 1999, p. 5-36. Disponível em: < http://ejt.sagepub.com/content/5/1/5.abstract > . Data de acesso: 05/11/2016

BETHELL, Leslie. O Brasil e a ideia de "América Latina” em perspectiva histórica, Estudos Históricos. vol. 22, $\mathrm{n}^{\circ}$ 44, 2009, p. 289-321. Disponível em: < http://www.scielo. br/pdf/eh/v22n44/v22n44a01.pdf > . Data de acesso: 05/11/2016.

BURGES, Sean. Revisiting consensual hegemony: Brazilian regional leadership in question, International Politics, vol. 52, $\mathrm{n}^{\circ}$ 2, 2015, p. 193-207. Disponível em: < http://link. springer.com/article/10.1057/ip.2014.43 > . Data de acesso: 05/11/2016. 
CERVO, Amado Luiz. Política exterior e relações internacionais do Brasil: enfoque paradigmático. Revista Brasileira de Política Internacional, Vol. 46, No. 2, 2003, p. 5-25. Disponível em: < http://www.scielo.br/pdf/rbpi/v46n2/v46n2a01.pdf > . Data de acesso: 05/11/2016.

CERVO, Amado Luiz. Inserção internacional: formação dos conceitos brasileiros. São Paulo: Saraiva, 2008.

CHARAUDEAU, Patrick; MAINGUENEAU, Dominique. Dicionário de Análise do Discurso. São Paulo: Editora Contexto, 2008.

CORRÊA, Luiz F. de Seixas. Diplomacia e História: política externa e identidade nacional brasileira. Política Externa. São Paulo, Vol. 9, No. 1, Jun/Ago 2000, p. 22-32.

DE CILLIA, R.; REISIGL, M.; WODAK, R. The discursive construction of national identities. Discourse \& Society. Vol 10, No. 2, 1999, p. 149-173. Disponível em: < http://uk.sagepub.com/sites/default/files/upm-binaries/40470_13b.pdf >. Data de acesso: 05/11/2016.

FERREIRA, Túlio Sérgio Henriques. O Universalimo e seus Descontentes: a política exterior do Brasil no governo Figueiredo (de 1979 a 1985). Curitiba: Juruá, 2009.

FELLET, João. Apesar de ação afirmativa, só 2,6\% dos novos diplomatas são negros. BBC Brasil. 21 de novembro de 2012. Disponível em: http://www.bbc.com/portuguese/ noticias/2012/11/121120_itamaraty_acoes_afirmativas_jf.shtml. Acesso: 16/08/2016.

FINNEMORE, Martha; SIKKINK, Kathryn. Taking stock: The Constructivist Research Program in International Relations and Comparative Politics. Annual Review of Political Science. Vol. 4, 2001, p. 391-416. Disponível em: < http://www.annualreviews.org/ doi/abs/10.1146/annurev.polisci.4.1.391 > . Data de acesso: 05/11/2016.

FLEMES, Daniel; WEHNER, Leslie. Drivers of strategic contestation: the case of South America, International Politics, vol. 52, $\mathrm{n}^{\circ} 2$, 2015, p. 163-177. Disponível em: < http://link.springer.com/article/10.1057/ip.2014.45 > . Data de acesso: 05/11/2016 FONSECA JR., Gelson. A legitimidade e outras questões internacionais. São Paulo: Paz e Terra, 1998.

GIDDENS, Anthony. A constituição da sociedade. São Paulo: Martins Fontes, 1984.

GUILLAUME, Xavier. Foreign Policy and the Politics of Alterity: A Dialogical Understanding of International Relations. Millennium - Journal of International Studies Vol. 31, No. 1, 2002, p. 1-26. Disponível em: < http://mil.sagepub.com/content/31/1/1. abstract $>$. Data de acesso: 05/11/2016.

GUZZINI, Stefano. A Reconstruction of Constructivism in International Relations. European Journal of International Relations. Vol. 6, No. 2, 2000, p. 147-182. Disponível em: < http://ejt.sagepub.com/content/6/2/147.abstract > . Data de acesso: 05/11/2016

HALL, Stuart. A identidade cultural na pós-modernidade. Rio de Janeiro: DP\&A Editora, 2006. 
HOPF, Ted. The Promise of Constructivism in International Relations Theory. International Security. Vol. 23, No. 1, Summer 1998, p. 171-200. Disponível em: < https://www. jstor.org/stable/2539267 > . Data de acesso: 05/11/2016 .

IANNI, Octavio. Pensamento social no Brasil. Bauru: EDUSC, 2004.

JANCSÓ, István; PIMENTA, João Paulo. Peças de um mosaico (ou apontamos para o estudo da emergência da identidade nacional brasileira). In: MOTA, Carlos Guilherme (org.). Viagem incompleta: a experiência brasileira (1500-2000). São Paulo: Editora SENAC, 2000, p. 127-176.

JENNE, Nicole; SCHENONI, Luis. Latin American declaratory regionalism: An analysis of presidential discourse (1994-2014). EUI Working Paper RSCAS 2015/53. 2015. Disponível em: < http://cadmus.eui.eu/bitstream/handle/1814/36395/ RSCAS_2015_53.pdf? sequence $=1>$. Data de acesso: 05/11/2016LAFER, Celso. A Identidade Internacional do Brasil e a Política Externa Brasileira: Passado, Presente e Futuro. São Paulo: Perspectiva, 2009.

LAZAROU, Elena.; THEODORO, Bruno. Regionalism as an instrument: assessing Brazil's relations with its neighbourhood, Global Society, vol. 29, $\mathrm{n}^{\circ}$ 3, 2015, p. 1-19. Disponível em: < http://dx.doi.org/10.1080/13600826.2015.1039500 > . Data de acesso: 05/11/2016.

LEITE, Dante Moreira. O Caráter Nacional Brasileiro: história de uma ideologia. 5 ed. São Paulo: Ática, 1992.

MAGNOLI, Demétrio, et al. Em busca do interesse nacional. Política Externa. São Paulo, Vol. 9, No. 1, Junho/Agosto 2000, p. 33-50.

MALAMUD, Andres; RODRIGUEZ, Júlio. Com um pé na região e outro no mundo: O dualismo crescente da política externa brasileira. Estudos Internacionais, Vol. 1, No. 2, 2013, p. 167-183. Disponível em: < http://periodicos.pucminas.br/index.php/ estudosinternacionais/article/view/6312/5791 > . Data de acesso: 05/11/2016.

MARCUSSEN et al. Constructing Europe? The evolution of French, British and German Nation-State Identities. 1999. Disponível em: < http://aei.pitt.edu/2326/ > . Data de acesso: 19 Jan. 2015.

MERKE, Frederico. Neither balance nor bandwagon: South American international society meets Brazil's rising power, International Politics, vol. 52, $\mathrm{n}^{\circ} 2$, 2015, p. 178-192. Disponível em: < http://link.springer.com/article/10.1057/ip.2014.49> . Data de acesso: 05/11/2016.

MERQUIOR, J. G. O Outro Ocidente, Presença. Rio de Janeiro, No. 15, 1990, p . 69-91 MESQUITA, Rafael. The hegemonic hermano: South American collective identity and Brazilian regional strategy, Canadian Journal of Latin American and Caribbean Studies. Vol. 41, No. 2, 2016, p. 215-238. Disponível em: < http://dx.doi.org/10.10 80/08263663.2016.1182691 > . Data de acesso: 05/11/2016. 
MESQUITA, Rafael; MEDEIROS, Marcelo de Almeida. Legitimising Emerging Power Diplomacy: An Analysis of Government and Media Discourses on Brazilian Foreign Policy under Lula. Contexto internacional. Vol. 38, $\mathrm{n}^{\mathrm{o}} 1$, 2016, p. 385432. Disponível em: < http://www.scielo.br/scielo.php?script=sci_arttext\&pid $=$ S0102-85292016000100385 $>$. Data de acesso: 05/11/2016.

MOURÓN, Fernando.; ONUKI, Janina. ¿Brasil es un líder en América del Sur? El papel brasileiro a través del concepto de liderazgo situacional. Estudos Internacionais, vol. 3, $\mathrm{n}^{\circ}$ 1, 2015, p. 9-25. Disponível em: < http://periodicos.pucminas.br/index. php/estudosinternacionais/article/view/9412/8954 > . Data de acesso: 05/11/2016

NEUMANN, Iver B. Self and other in international relations. European Journal of International Relations. Vol. 2 No. 2, 1996, p. 139-174. Disponível em: < http://ejt. sagepub.com/content/2/2/139.abstract > . Data de acesso: 05/11/2016.

ONUKI, Janina; MOURON, Fernando; URDINEZ, Francisco. Latin American Perceptions of Regional Identity and Leadership in Comparative Perspective. Contexto internacional. vol. 38, no 1, 2016, p. 45-77. Disponiível em < http://dx.doi.org/10.1590/S01028529.2016380100012 > . Data de acesso: 05/11/2016.

ORLANDI, Eni p. Análise de discurso. $7^{\text {a }}$ ed. São Paulo: Pontes, 2007.

ORTIZ, Renato. Imagens do Brasil. Revista Sociedade e Estado. Vol. 28, N. 3, Setembro/ Dezembro, 2013, p. 609-633. Disponível em: < http://www.scielo.br/pdf/se/v28n3/ a08v28n3.pdf > . Data de acesso: 05/11/2016.

PEREYRA-DOVAL, Gisela. La formación del Estado brasileño y los usos de su política exterior a la luz del proceso de construcción identitaria. La definición de situaciones clave. Civilizar, Vol. 13, No. 25, 2013, p. 49-66. Disponível em: < http://www.scielo. org.co/pdf/ccso/v13n25/v13n25a05.pdf > . Data de acesso: 05/11/2016.

PEREYRA-DOVAL, Gisela; ROMERO, Pedro. Entre el temor y el amor: Percepciones argentinas sobre Brasil como poder mundial. Latin American Journal of International Affairs. Vol. 5, N. 2, 2013, p. 01-21. Disponível em: < http://www.lajia.net/ volumenes/LAJIA \% 20vol5 \%20n2\%20Art01.pdf?attredirects $=0 \& d=1>$. Data de acesso: 05/11/2016.

PINHEIRO, Letícia; GAIO, Gabrieli. Cooperation for Development, Brazilian Regional Leadership and Global Protagonism. Brazilian Political Science Review. vol. 8, $\mathrm{n}^{\circ} 2$, 2014, p. 8-30. Disponível em: < http://dx.doi.org/10.1590/1981-38212014000100009 > . Data de acesso: 05/11/2016.

POSSENTI, Sírio. Os limites do discurso: ensaios sobre discurso e sujeito. São Paulo: Parábola Editorial, 2009.

PRADO, Maria Ligia Coelho.. O Brasil E a Distante América Do Sul. Revista De História, Vol. 145, 2001, p. 127-149. Disponível em: < http://dx.doi.org/10.11606/issn.23169141.v0i145p127-149 > . Data de acesso: 05/11/2016. 
PRYS, Miriam. Developing a Contextually Relevant Concept of Regional Hegemony: The Case of South Africa, Zimbabwe and "Quiet Diplomacy”. GIGA Working Papers N. 77, May 2008. Disponível em: < https://www.giga-hamburg.de/de/system/files/ publications/wp77_prys.pdf > . Data de acesso: 05/11/2016.

RIBEIRO, Darcy. O povo brasileiro: a formação e o sentido do Brasil. São Paulo: Companhia de Bolso, 2006.

RISSE, Thomas. Let's Argue!: communicative action in world politics. International Organization. Vol. 54, No. 1, 2000, p. 1-39. Disponível em: < https://doi.org/10.1162/ 002081800551109 > . Data de acesso: 05/11/2016.

ROUQUIÉ, Alain. Amérique Latine: introduction à l'extrême-occident. Paris: Seuil, 1987. ROUQUIÉ, Alain. Le Brésil au XXIe siècle: naissance d’un nouveau grand. Paris: Fayard, 2006. SANTOS, Luís Cláudio Villafañe G. A América do Sul no discurso diplomático brasileiro. Revista Brasileira de Política Internacional, Vol. 48, N. 2, 2005, p. 185-204. Disponível em: < http://dx.doi.org/10.1590/S0034-73292005000200010 > . Data de acesso: 05/11/2016. SANTOS, Luís Cláudio Villafañe G. O dia em que adiaram o Carnaval: política externa e a construção do Brasil. São Paulo: Unesp, 2010.

SANTOS, Luís Cláudio Villafañe G. A América do Sul no discurso diplomático brasileiro. Brasília: FUNAG, 2014.

SARAIVA, Miriam Gomes. A diplomacia brasileira e as visões sobre a inserção externa do Brasil: institucionalistas pragmáticos x autonomistas. Mural internacional, Vol. 1, No. 1, 2010, p. 45-52. Disponível em: < http://www.e-publicacoes.uerj.br/index.php/ muralinternacional/article/view/5285 > . Data de acesso: 05/11/2016.

SCHAEBLER, Birgit. Civilizing Others: Global Modernity and the Local Boundaries (French/ German, Ottoman and Arab) of Savagery. In.: SCHAEBLER, Birgit; STENBERG, Leif (eds.) Globalization and the Muslim World: culture, religion, and modernity. Syracuse: Syracuse University, 2004, p. 3-29.

SOMBRA SARAIVA, José Flávio. O Brasil e a integração hemisférica: vertente histórica. Em Aberto, Vol. 15, No. 68, 1995, p. 36-44.

SPEKTOR, Matias. Ideias de ativismo regional: a transformação das leituras brasileiras da região, Revista Brasileira de Política Internacional, vol. 53, No. 1, 2010, p. 25-44. Disponível em: < http://dx.doi.org/10.1590/S0034-73292010000100002 > Data de acesso: 05/11/2016.

STEINER, Andrea Quirino.; MEDEIROS, Marcelo de Almeida.; LIMA, Rafael Mesquita de Souza. From Tegucigalpa to Teheran: Brazil's diplomacy as an emerging Western country. Revista Brasileira de Política Internacional, Brasília, Vol. 57, No. 1, 2014. Disponível em: < http://www.scielo.br/pdf/rbpi/v57n1/0034-7329-rbpi-57-01-00040.pdf > . Data de acesso: 05/11/2016. 
TEIXEIRA, C. Brazil and the institutionalization of South America: from hemispheric estrangement to cooperative hegemony, Revista Brasileira de Política Internacional, vol. 54, $\mathrm{n}^{\circ}$ 2, 2011, p. 189-211. Disponível em: < http://dx.doi.org/10.1590/S0034$73292011000200010>$. Data de acesso: 05/11/2016.

TUSSIE, Diana. Presidential diplomacy in UNASUR: coming together for crises management or making turfs? In: MACE, Gordon; JEAN-PHILIPPE, Thérien; TUSSIE, Diana; DABÈNE, Olivier. (eds) Summits and regional governance: the Americas in comparative perspective. New York: Routledge, 2016, p. 71-87.

VAN LANGEHOVE, Luk; ZWARTIES, Marieke; PAPANAGNOU, Georgios. Conceptualising Regional Leadership: The Positioning Theory Angle. In KINGAH, Stephen; QUILICONI, Cintia (eds.) Global and Regional Leadership of BRICS countries. Springer. 2016.

VIGEVANI, Tullo; CEPALUNI, Gabriel. A política externa brasileira: a busca da autonomia, de Sarney a Lula. São Paulo: Editora Unesp, 2011.

WENDT, Alexander. Anarchy is what states make of it: the social construction of power politics. International organization. Vol. 46, No. 2, 1992, p. 391-425. Disponível em: < https://www.jstor.org/stable/2706858 > . Data de acesso: 05/11/2016.

WENDT, Alexander. The Agent-Structure Problem in International Relations Theory. International Organization, Vol. 41, No. 3, 1987, p. 335-370. 